Alexander Nagel

Christopher S. Wood

Renacimiento anacronista

422 págs. Madrid:

Akal, 2017

ISBN 978-84-460-4507-6

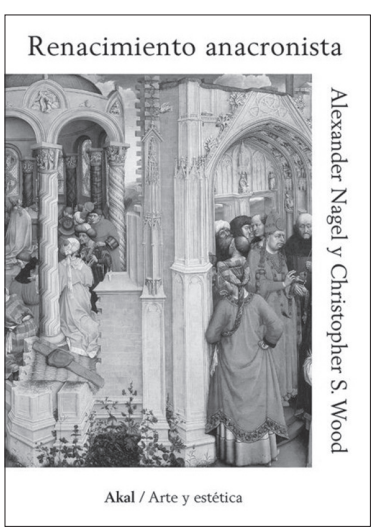

\section{JosÉ RIELLO}

$\mathrm{S}^{\mathrm{i}}$ empre me ha llamado la atención que en los planes de estudio de las carreras de humanidades no haya asignaturas específicas dedicadas al concepto de «tiempo», y más incluso que los historiadores no se hayan preguntado sobre el significado del tiempo tan a menudo como tal vez debieran. Como historiadores, y en última instancia como responsables de los planes de estudio a los que me refería, asumen que el tiempo existe como una obviedad, pero también debería serlo que los modos en que el tiempo existe o, dicho de otra manera, los modos en que marcamos su paso, están lejos de ser naturales o neutrales. Quizá todo esto haya sido fruto del triunfo de la modernidad y, con ella, del triunfo del historicismo, sobre todo si entendemos que "'modernity' is first and foremost a set of notions about and experiences of temporality», ${ }^{1}$ y esta, la temporalidad moderna, es la que otorga los fundamentos a las humanidades. En el proyecto moderno, el tiempo es universal, homogéneo y profundo, en el sentido de que viene de muy atrás —en el propio tiempo-; tiene significados seculares y naturales, y no divinos o sobrenaturales; y permite proyectar nuevas relaciones con el futuro - progresar, por ejemplo—. ${ }^{2}$ Pues bien: hemos asumido estas características de tal modo que parece que fueran naturales y, por ello, que no hubiera ahora o no hubiera habido antes concepciones alternativas del tiempo. Por esa razón puede resultar más estimulante - y más difícil, también— la lectura de libros como el que Alexander Nagel y Christopher S. Wood publicaron en 2010 por vez primera (Nueva York, Zone Books) y que ahora, siete años después, se ha traducido al español en la colección «Arte y estética» que dirige Joan Sureda para Akal. Y es que este libro ya desde el título plantea la posibilidad de pensar el tiempo en otros términos, distintos a los acostumbrados, aunque sea para un período histórico concreto, como es el Renacimiento. Como los autores afirman, «el tiempo cronológico, que fluye regularmente desde el antes hasta el después, es un efecto de sus figuraciones: anales, crónicas, calendarios, relojes», pero «no se trata de un concepto obvio» (pág. 7), luego

1. Hunt, L., Measuring Time, Making History. Budapest - Nueva York: Central European University Press, 2008, pág. 22.

2. Ibidem, pág. 25. cabría esperar que todos seamos también fruto de esas mismas figuraciones, porque a través de ellas nos han enseñado y hemos aprendido a pensary a usar el tiempo - un determinado concepto del tiempo- de una manera, y no de otra.

Y digo que se plantea desde el título porque decidieron emplear en él el término «anachronic» —-traducido en la versión en español por «anacronista»—, pero no porque les pareciera que el Renacimiento es un período anacrónico, sino por dos razones: la primera, evitar la connotación peyorativa de «anachronism $»^{3}$ que, en cambio, sí emplearon en la primera redacción de sus propuestas; ${ }^{4}$ la segunda, remitir a los distintos modos de recrear el tiempo que se conjugaron en el Renacimiento situándose más allá de una secuencia lineal -o cronológica - del mismo. El propio objeto de estudio del libro condiciona su estructura misma, pues salvo el primer capítulo («La temporalidad plural de la obra de arte»), el tercero («¿Qué es sustitución?») y el quinto («El plebeyo placer del anacronismo»), los veinticinco restantes se suceden sin seguir un orden cronológico, solapándose como secciones que se pliegan sobre sí mismas y en torno a estudios de caso que abarcan desde las estampas devocionales hasta las imágenes milagrosas, los mosaicos, los pavimentos cosmatescos, el titulus de la cruz de Cristo, el retrato en medallas, relicarios y reliquias y, por supuesto, edificios y pinturas, todos ellos fechados entre el siglo XII y comienzos del xvI, y no solo de Italia, sino también del norte de Europa. Estamos, por tanto, ante una concepción expandida del Renacimiento pero que, a tenor de los ejemplos recopilados, hace especial hincapié en las dos últimas décadas del siglo XV.

En este sentido, el libro de Nagel y Wood contribuye a lo que Hal Foster ha llamado la «rehabilitación del anacronismo $»^{5}$ que han acometido, o siguen haciéndolo, autores como George Didi-Huberman ${ }^{6}$ y Mieke Bal, ${ }^{7}$ no solo por sus

3. «La obra de arte, cuando llega tarde, cuando repite, cuando vacila, cuando recuerda, pero también cuando proyecta un futuro o un ideal, es "anacronista" [anachronic]. Aportamos este término como una alternativa a "anacrónico" [anachronistic], un término enjuiciador que lleva consigo la asunción historicista de que cada acontecimiento y cada objeto tienen su propio lugar dentro de un tiempo objetivo y lineal» (pág. 12).

4. Habían adelantado lo esencial en NAgEL, A.; Wood, C.S., «Toward a New Model of Renaissance Anachronism», The Art Bulletin, vol. 87, 3, 2005, págs. 403-415; ya entonces provocaron estupendas respuestas en el mismo número de la publicación de DeMPseY, C., «Response: Historia and Anachronism in Renaissance Art», págs. 416421; Cole, M., «Response: Nihil sub Sole Novum», págs. 421-424; y FARAGO, C., «Response: Time Out of Joint», págs. 424-429, a quienes a su vez contestaron en NAGEL, A.; WooD, C.S., «The Authors Reply», págs. 429-432. Retomaron su postura, con nuevos matices, en NAGEL, A.; WooD, C.S., «What Counted as an "Antiquity" in the Renaissance?», en EISEnBICHLER, K. (ed.), Renaissance Medievalisms. Toronto: Centre for Reformation and Renaissance Studies, 2009, págs. 53-74.

5. Foster, H., «Preposterous Timing», London Review of Books, vol. 34, 21, 8 de noviembre de 2012, págs. 12-14.

6. A quien se lee, cuando no se idolatra, más que se le entiende en España. Nagel y Wood remiten (pág. 10, n. 14) a Devant l'image: question posée aux fins d'une histoire de l'art. París: Les Éditions de Minuit, 1990; Devant le temps: histoire de l'art et anachronisme des images. París: Les Éditions de Minuit, 2000; y L'image survivante: Histoire de l'art et temps des fantômes selon Aby Warburg. París: Les Éditions de Minuit, 2002. Los tres libros están traducidos al español.

7. BAL, M., Quoting Caravaggio: Contemporary Art, Preposterous History. Chicago: Chicago University Press, 1999. 
propias elaboraciones teóricas, sino también por contribuir a rescatar a historiadores y filósofos del pasado siglo que significativamente fueron arrumbados por el discurso historiográfico hegemónico. Son conocidas la vindicación de Aby Warburg que se ha producido en las últimas décadas -incluso, aunque con retraso, en España-, a la que también han contribuido Nagel y Wood con su libro; revitalizaciones como la de Walter Benjamin, que subyace así mismo en las páginas que comento; o redescubrimientos como el de Carl Einstein. A la espera, todavía, se mantienen otros, como Henri Focillon o George Kubler. Aun con notables diferencias entre sí, todos ellos habrían sugerido alternativas para conceptualizar el tiempo y habrían concebido el anacronismo menos como la proyección de un prejuicio contemporáneo sobre un objeto del pasado - lo que constituiría el más irremisible pecado del historiador, como aseveró Lucien Febvre-, y más como el reconocimiento de la compleja temporalidad que caracteriza a esos objetos, y en particular a las obras de arte.

En efecto, los artefactos que identificamos como obras de arte tienen la capacidad de escapar de las circunstancias temporales en que fueron creados para seguir siendo significativos - para seguir creando significado- en diferentes momentos y distintos lugares: pertenecen al pasado y al presente, y se proyectan hacia el futuro. En palabras de los autores:

... ningún otro dispositivo genera más eficazmente el efecto de un desdoblamiento o de una curvatura del tiempo que la obra de arte, un tipo de acontecimiento extraño cuya relación con el tiempo es plural. La obra de arte es fabricada o diseñada por un individuo o un grupo de individuos en un momento dado, pero, al mismo tiempo, también apunta hacia el pasado, tal vez hacia un origen ancestral remoto o hacia un objeto previo, o hacia un origen divino, situado fuera del tiempo. A la vez apunta hacia todos sus receptores futuros que la activarán y reactivarán en tanto acontecimiento lleno de sentido. La obra de arte es un mensaje cuyo emisor y destinatario están continuamente desplazándose. $^{8}$

Esta relación de los objetos históricos con el tiempo, en particular de las obras de arte, obliga a replantear los fundamentos epistemológicos de la disciplina de la Historia del Arte, que necesariamente ha de abrirse a otras disciplinas - en particular, la Antropología y la Semiología - para promover una redefinición radical de la naturaleza y la función de sus objetos de estudio, ya no solo como objetos artísticos, sino también como objetos de cultura en un sentido amplio. Como tales, habría que considerar el alcance y la complejidad del papel que desempeñaron en la fundamentación de creencias o el establecimiento de rituales, su relevancia simbólica pero también material ${ }^{9} \mathrm{y}$, por qué no,

8. NAGEL, A.; Wood, C.S., Renacimiento anacronista. Madrid: Akal, 2017, págs. 7 y 8.

9. Algunas de estas cuestiones ya fueron adelantadas por el historiador del arte más relevante en la actualidad, a pesar de que falleciera en 2008: Michael Baxandall. Por limitarme a la época que nos compete, véase ese libro fascinante que es The Limewood Sculptors of Renaissance Germany. New Haven - Londres: Yale University Press, 1980. su eficacia política - no por partidista, que también, sino por su capacidad para generar interacciones sociales-. A su vez, esta nueva perspectiva epistemológica conllevaría la desmitificación de la concepción humanista de las obras de arte y la deconstrucción de la disciplina de la Historia del Arte tradicional, fundada en categorías como «invención», que constituye a la obra de arte en un objeto único; «imitación» o «mímesis», vertebradora del arte occidental desde sus orígenes míticos; $\mathrm{y}$ «culto al autor», uno de los caballos de batalla, por cierto, de Nagel y Wood. Lo que subyace en su libro es la idea de que el reconocimiento de una distancia insalvable habría permitido a los humanistas del Renacimiento concebir la existencia de una Edad Media que los separaba de la cultura antigua, y que podrían atenuar tal distancia con su recuperación a través de la imitación y, sobre todo, la emulación; esto, a su vez, habría promovido la concepción moderna del tiempo y, con ella, la posibilidad de establecer distinciones temporales precisas.

Dos habrían sido los modelos historiográficos fundados en esta fractura. El primero es el biológico-biográfico instituido por Giorgio Vasari con sus Vite - en sus dos ediciones, de 1550 y 1568-, en el que esos objetos de cultura se habrían convertido en objetos artísticos que jalonan la vida de un artista relacionándose, a su vez, con obras anteriores, coetáneas o incluso posteriores - sin saberlo- propias o realizadas por otros artistas, y así sucesivamente y ad infinitum. Nagel y Wood llegan a afirmar que «el Renacimiento - la recreación de los logros culturales de los antiguos- se construyó sobre falsas premisas» (pág. 157), un Renacimiento que habría sido una época de plenitud ajena a toda impureza, a toda interferencia. Después habrían llegado «los teóricos modernos» a quienes habría resultado «conveniente conservar el mito de un Renacimiento prosaicamente historicista» (pág. 49) según una concepción que tendría un responsable principal: Erwin Panofsky. ${ }^{10}$ Frente a los medievalistas, Panofsky habría defendido el surgimiento de una nueva visión del pasado, y en especial del pasado antiguo, en el Renacimiento, pues solo a partir del siglo XV se habría visto el mundo antiguo desde una fija e inmutable distancia en el tiempo, y por tanto habría sido «el primer período capaz de ver el arte histórico en perspectiva» (pág. 49). Dicho de otro modo: para Nagel y Wood, el modo en que las personas del Renacimiento pensaban, o sea, vivían, no tiene nada que ver con el Renacimiento lineal y racional de Panofsky; la perspectiva sería una forma simbólica más para nosotros que para ellos. ${ }^{11}$ El triunfo del modelo vasariano y del modelo panofskiano habría llevado a censurar los procesos que cuestionan la autenticidad y la unidad de la obra de arte, y a olvidar prácticas y procesos de significación mucho más complejos, contradictorios incluso, en los que invención y reproducción coexistirían sin enfrentarse o neutralizarse y, con ellas, la posibilidad de que hubiera existido un Renacimiento más intuitivo y menos racional.

10. Desde Panofsky, E., «Renaissance and Renascences», The Kenyon Review, vol. 6, 2, 1944, págs. 201-236, hasta, por supuesto, idem, Renaissance and Renascences in Western Art. Estocolmo: Almqvist \& Wiksell, 1960.

11. Es sintomático el parco, cuando no nulo, papel que desempeña el método iconológico en el libro. 
Al final del primer capítulo que, como decía, funciona en el libro como una suerte de introducción, los autores afirman que

los veintiocho capítulos de este libro dibujan un modelo conceptual de cierta flexibilidad, que acoge potencialmente cualquier cosa edificada o pintada entre los siglos XIV y xvI. Este libro no es $l a$ historia del Renacimiento, pero tampoco es una historia más. Imagina la infraestructura de muchas historias posibles. ${ }^{12}$

Semejante infraestructura iría más allá de la Historia del Arte oficial, pero a su vez aspiraría a poder ser aplicada universalmente como un paradigma que trascendiera nada menos que el «modelo de una obra de arte firmemente anclada en el tiempo histórico, el modelo que domina el estudio académico del arte» ${ }^{13}$ y que quedó institucionalizado:

entre finales del siglo XVI y el siglo XVIII, por tratados sobre el arte, historiadores del arte, catálogos de colecciones, la aparición de los marchantes profesionales, el establecimiento de los mercados de arte y la creación de las academias de arte. ${ }^{14}$

La infraestructura teórica de la que hablan Nagel y Wood se acomoda a la perfección al período histórico elegido, ese Renacimiento caracterizado por su naturaleza anacronista, que no anacrónica, pues entonces se habrían desarrollado dos modelos de producción de obras de arte o, mejor, de artefactos en un sentido amplio, cuya coexistencia solo fue posible en parte del Renacimiento. De hecho, la naturaleza anacrónica de la obra de arte del Renacimiento radicaría en que podía dejar en suspenso estos dos modelos creativos que, en principio, no son compatibles: por un lado, el modelo sustitutivo - substitutional-; por otro, el modelo realizativo —-según la traducción elegida para performative-. Este segundo habría sido el puesto en práctica por una persona determinada — el artista - en un momento fijado - la fecha- para realizar un artefacto concreto - la obra de arte-, que sería, pues, un producto autorial caracterizado por una cualidad temporal; ni que decir tiene que este modelo realizativo se corresponde con nuestro modo habitual de concebir las obras de arte, como creaciones de un autor en una fecha determinada. En cambio, el primer modelo o sustitutivo remitiría a una concepción del artefacto como un eslabón más de una cadena cuyo origen estaría en un prototipo - por ejemplo, un icono como el de Santa Maria del Popolo en Roma (capítulo 11) o un edificio como la Santa Casa de Loreto (capítulo 18) - que, en tanto que orígenes de la cadena, habrían sido inventados retrospectivamente:

Percibir un objeto desde un punto de vista sustitutivo era entenderlo como perteneciente de manera simultánea a más de un momento histórico. El objeto estaba conectado a su ignoto punto de origen por una cadena de réplicas imposible de reconstruir. $^{15}$

12. NAGEL, A.; WooD, C.S., Renacimiento anacronista, págs. 18 y 19; las cursivas son suyas.

13. Ibidem, pág. 10

14. Ibidem, pág. 18.

15. Ibidem, pág. 30.
Cada eslabón de la cadena sería, respecto al prototipo, una reactivación o una actualización de este y, por esa razón, «el "arte renacentista" fue una máquina para producir “arte medieval”» (pág. 27). En contra de la comprensión cronológica del tiempo en el que los acontecimientos se desenvuelven o acontecen a lo largo, valga la redundancia, de una línea del tiempo, y en el que la obra performativa o realizativa sería una cesura, la obra sustitutiva plegaría el tiempo subrayando las continuidades y las secuencias a la par que su carácter de testimonio. Las relaciones entre las obras sustitutivas y sus prototipos primevos serían de orden tipológico, y la continuidad entre Medievo y Renacimiento sería mucho mayor de lo que - aún- estamos dispuestos a reconocer. La cuestión solo se resolvería a comienzos del siglo XVI, cuando «ya es prácticamente posible definir la autoría artística como la capacidad de manipular los dos modos [realizativo y sustitutivo] dentro de los confines de un campo estético» (pág. 55).

En 1990, Hans Belting propuso una nueva evolución del arte europeo desde las imágenes de culto (Bild), cuyo poder radica en su capacidad para hacer presente a la divinidad, a las obras de «arte» (Kunst), que habrían reemplazado progresivamente a aquellas. ${ }^{16}$ Frente a su tesis, Nagel y Wood defienden que la imagen de culto no habría cedido ante el desarrollo prodigioso del arte, sino que «más bien la Bild era un mito retrospectivo inventado por el Kunst» (pág. 136), de modo que el antiguo modelo sustitutivo habría continuado siendo operativo y habría convivido con el nuevo modelo de la obra de arte auténtica y original, expresión de la individualidad de un artista. En el mundo medieval tardío y durante el siglo Xv, las obras de arte se habrían caracterizado por su temporalidad múltiple, oscilante entre el presente y un lejano pasado. A esa misma temporalidad ambigua pertenecerían las obras originarias de las que procederían las réplicas posteriores que, como una reliquia respecto a su original, conservarían rasgos esenciales o incluso restos materiales de sus arquetipos. De ese modo, las obras de arte ya no quedarían ancladas a un tiempo preciso, ligado a la época de su ideación, creación y concreción material, sino que serían más bien objetos estructurales, elementos de una cadena que re-produciría un prototipo originario del que descienden; las obras serían re-proposiciones de un original, y su autoridad procedería del contacto directo - real o imaginario, lo mismo da-con su referente. ${ }^{17}$ Este pudo perderse en un pasado lejano — de hecho, es lo que suele ocurrir-, pero su existencia sería postulada como la única fuente legítima de la autoridad de las obras posteriores que, sin embargo, por definición serían sustituibles indefinidamente sin que sus diferencias estéticas y las circunstancias específicas de su ideación, su creación y su

16. Belting, H., Bild und Kult: Eine Geschichte des Bildes vor dem Zeitalter der Kunst. Múnich: C. H. Beck'sche Verlagbuchhandlung (Oscar Beck), 1990. Fue traducido al español en las mismas editorial y colección en que se ha publicado el libro que comento: idem, Imagen y culto. Una historia de la imagen anterior a la edad del arte. Madrid: Akal, 2009.

17. «Pensar "estructuralmente", entonces y ahora, es rechazar la cronología lineal como la matriz inevitable de la experiencia y de la cognición»; NAGEL, A.; WooD, C.S., Renacimiento anacronista, pág. 7 . 
concreción material pudieran interferir en su funcionamiento o en su capacidad para hacer presente el pasado. Sin embargo, el desencantamiento y la secularización del relato histórico habrían relegado esta capacidad que las obras de arte tienen para plegar el tiempo.

La tesis primordial del libro, pues, es que ciertos artefactos habrían sido percibidos y usados como antiguos con independencia de si fueron producidos en una época reciente o cercana o, dicho de otro modo, serían anacrónicos, temporalmente inestables y, a la vez, jalones en una línea del tiempo convencionalmente cronológica. Por ello no puede extrañar que Nagel y Wood aborden problemas de tanto calado - y que su libro ha contribuido a considerar como casi inéditos campos de estudio-como las falsificaciones, las copias, los pastiches, las réplicas ${ }^{18} \mathrm{y}$ los spolia, cuando no problemas como el papel que desempeñaron los iconos bizantinos en Europa desde finales del siglo XIII hasta el XV -incluso más allá, si pensamos en un artista que ellos no citan y que es fundamental desde este punto de vista: el Greco-, la relevancia de la imprenta o, como apuntaba antes, la función «autor», como habría dicho Michel Foucault. El libro de Nagel y Wood pretende desentrañar los mecanismos por los cuales ese tráfico se reactiva y la tensión y la coexistencia que se produjeron entre los modelos sustitutivo y realizativo entre finales del siglo XII y comienzos del Xvi. Si el modelo de sustitución permitiría que el tiempo de una imagen llegara a ser inconsecuente y no fuera necesario remitir a una localización temporal, el realizativo, con su insistencia en la importancia del autor, solo tendría sentido en una narración cronológica:

La capacidad de la obra de arte de mantener en suspenso modelos incompatibles sin decidir entre ellos es la clave de su carácter anacronista, de su habilidad para realmente «atrapar» un pasado, para crear un pasado, tal vez incluso para atrapar el futuro. Estos poderes anacronistas no se deben completamente ni al modelo de sustitución ni al modelo de autoría. La obra de arte es algo más que la suma de sus propios mitos sobre el origen [...]. El arte, un sistema recursivo, es una vacilación sobre la vacilación. $^{19}$

En definitiva, la arriesgada y vocacionalmente polémica propuesta de Nagel y Wood pone sobre la mesa de juego una serie de herramientas y reflexiones acerca del pasado que, tal vez, son menos esquemáticas que las de los viejos modelos historiográficos, pues podrían asumir las contradicciones, las ambigüedades, las resistencias o las discontinuidades más allá de la retórica del progreso y de la concep-

18. No es casual que Wood hubiera consagrado todo un libro a estas cuestiones: Wood, C.S., Forgery, Replica, Fiction: Temporalities of German Renaissance Art. Chicago: Chicago University Press, 2008. 19. NAGEL, A.; Wood, C.S., Renacimiento anacronista, pág. 17. ción lineal del tiempo y, con ellas, de la historia que aún predomina en el discurso historiográfico. Es por esta razón, esencialmente, por lo que me llama poderosamente la atención que apenas haya mención en el libro a circunstancias sociales, económicas, políticas, ni siquiera históricas o religiosas, tal vez por el deseo de los autores de escapar a una determinada Historia del Arte que ha prestado, quizá, excesiva atención al contexto como explicación causal de las obras de arte del pasado. Como apuntan al principio de forma bellísima:

La palabra «arte» designa la posibilidad de una conversación a través del tiempo, una conversación con más sentido que la mera reconstrucción forense del pasado por parte del presente. Un enfoque materialista del arte histórico deja el arte atrapado dentro de sus circuitos simbólicos originales. ${ }^{20}$

Pero ese enfoque sobre esas circunstancias sociales, económicas, políticas, incluso históricas o religiosas, cuando no sobre la retórica o los discursos teóricos entre los siglos XII y XVI, importa. ${ }^{21}$ E importa mucho. Podrán aducirse muchos ejemplos, pero para lo que aquí se trata, solo mencionaré uno en el que es palmaria la conciencia que los hombres del Renacimiento tenían de estar viviendo un nuevo tiempo que se fundamentaba en una nueva concepción temporal, y también una nueva situación material: la dedicatoria a Filippo Brunelleschi que Leon Battista Alberti incluyó en su redacción italiana del De pittura (c.1435).

Por fortuna, la pregunta sobre qué sea eso del Renacimiento sigue abierta, y el libro de Nagel y Wood ha contribuido de manera muy notable - probablemente como pocos otros lo han hecho en las dos primeras décadas del siglo XXI- a reactivar y refrescar el debate. A su vez, la «rehabilitación del anacronismo» de la que hablaba Foster nos empuja al borde de un abismo, y en particular en España, donde me temo que hemos entendido bastante poco de lo que podría suponer tal rehabilitación: ¿ cómo y cuánto de lejos queremos asomarnos a ese abismo ?22

20. Ibidem.

21. Como dice con mucha gracia Kristen Lippincott en su recensión al libro de Nagel y Wood, preguntándose si es posible hablar de creación y recepción de imágenes sagradas desde una perspectiva puramente teórica sin remitirse a la verdadera naturaleza de la creencia religiosa en los siglos XV y Xvi: «One does not have to be a reviled 'historicist' to argue that even though you can take the painting out of the church, is it certainly 'anachronistic' to take 'the Church' out of the painting»; LIPPINCOTT, K., "Anachronic Renaissance by Alexander Nagel and Christopher S. Wood», The Burlington Magazine, vol. 154, 1308, marzo de 2012, pág. 205.

22. Véanse por ejemplo las reflexiones de George Didi-Huberman sobre Fra Angelico en un libro que habla más del autor que del pintor, o lo que el propio Alexander Nagel cuenta en Medieval Modern: Art Out of Time. Londres: Thames \& Hudson, 2012. 